\title{
Effects Of Personality On Attitudes Toward Academic Group Work
}

William R. Forrester, Kennesaw State University, USA

Armen Tashchian, Kennesaw State University, USA

\begin{abstract}
This study investigated the effects of personality on attitudes toward academic group work among a sample of 225 business students. Data were collected using pre-existing scales for measuring personality and attitudes toward academic group work. Specifically, the Neo-FFI scale was used to measure the five personality dimensions of openness, agreeableness, extroversion, conscientiousness and neuroticism. Regression analysis indicated that extroversion was the best predictor of respondents' attitudes toward academic group work. Individuals with high extroversion scores had positive attitudes toward academic group work. Neuroticism, agreeableness and conscientiousness were also related to respondents' preference for group work and discomfort with group work. Interestingly, respondents' level of openness had no impact on any of the work group attitude variables.
\end{abstract}

Keywords: personality, group work, Neo-FFI, attitudes

\section{INTRODUCTION}

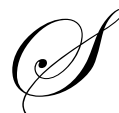

tudent project groups play an important role in the development of skills and attitudes toward team work that transcend the learning environment and affect the professional practices of graduates (McCorkle et. al. 1999; Huff, Cooper, and Jones 2002). Because academic group work has such notable effects on the development of work-relevant skills and attitudes, considerable research attention has been directed toward understanding group work attitudes and the ways in which skills and attitudes are affected by group work process and outcomes (Gardner and Korth 1998). In spite of these efforts, business schools have been criticized for not adequately preparing students with teamwork related skills and attitudes (Kaenzig, Hyatt, and Anderson 2007).

Desirable attitudes toward student group work include beliefs that group work helps learning, helps in the productive use of time, and aids learning retention. They reflect enjoyment at participating in group work and feel that group work is easier and more interesting than working alone. Additional desirable attitudes include feelings of relaxation while working in group settings and confidence in one's ability to make a personal contribution to group outcomes (Cantwell and Andres 2002). Past research has shown that positive attitudes toward group work are associated with higher levels of sociability, lower levels of social anxiety, stronger mastery of performance goals, and higher levels of learning awareness (Cantwell and Andrews 2002).

Considerable research effort has been directed toward understanding group work attitudes and the ways in which skills and attitudes are affected by group work processes and outcomes (Gardner and Korth 1998). This research has clarified ways in which group work attitude is influenced by situational, motivational, and experiential factors. Research has also linked personality tendencies with attitudes toward group work. A study by Thompson, Anitsal, and Barrett (2008) showed that group work orientation is affected by the tendency toward individualism versus collectivism and group members' comfort and satisfaction in working collectively rather than individually. Cantwell and Andrews (2002) showed that higher levels of sociability were associated with lower levels of social anxiety, higher levels of preference for group work, and higher levels of group task performance. Other studies have shown that personality mediates the relationship between achievement orientation and engagement in competitive versus cooperative behaviors (Ross, Rausch, Canada 2003). 
While past research has produced considerable evidence of personality effects, concern remains about the degree to which results can be generalized. Kickul and Neuman (2000), for example, cautioned that the group work literature has over-generalized findings about personality and called for research into the links between specific personality characteristics and attitude components that influence group work performance. This paper attempts to overcome this shortcoming by examining the influence of specific personality dimensions on indicators of group work appropriate for use with business student groups (Gardner and Korth, 1998, Cantwell and Andrews 2002).

For purposes of this study, personality is conceptualized in accordance with the five-factor model. The five-factor model is well established in the business literature and has been validated against many different criteria including job performance, job satisfaction, and career success. It is particularly well suited for use in this study since it has also been validated against the criterion of academic performance (Lounsbury, et. al. 2009).

Attitude toward academic group work is measured using scales developed by Cantwell and Andrews (2002) and Gardner and Korth (1998). Cantwell and Andrews use an 11-item scale that measures preference for group work and discomfort in group work. Similarly, Gardner and Korth use a series of seven items to tap attitudes toward academic group work. All scales are reported to have adequate psychometric properties.

\section{BACKGROUND RESEARCH}

The five-factor model of personality is a comprehensive model that views personality as a multidimensional construct consisting of five components identified as agreeableness, conscientiousness, neuroticism, extraversion, and openness to experience. These five dimensions have proven to be stable across diverse populations in a variety of research settings. They have also demonstrated strong predictive validity. Research has produced considerable evidence that individual differences in the five factors account for differences in the ways people think, feel, and interact with others.

The model associates these five dimensions with specific personality traits and allows prediction of personality differences among individuals (Costa and McCrae 1992). According to the model, individuals high in extroversion are likely to be gregarious, assertive, and sociable in contrast with introverts who are likely to be reserved, timid and quiet. Agreeableness can be thought of as the opposite of antagonism. Agreeable people are likely to be cooperative, warm, understanding, and sympathetic and unlikely to be rude, harsh, insincere, and unsympathetic. Similarly, those high in conscientiousness are likely to be hard working, well organized, dependable and firm while those less conscientious are likely to be lazy, disorganized, unreliable, and indecisive. Openness to experience encompasses reflectiveness, creativity, and comfort with theory in contrast with closeness which reflects conservativism of opinions, practicality, and resistance to change. Neuroticism describes tension, insecurity, and irritability in contrast with emotional stability which describes individuals who are calm, self confident, and patient.

Research in organizational behavior has associated differences in each of these personality factors with differences in group work attitudes and behaviors. Extroversion, for example, has been linked to higher levels of engagement in group leadership behavior (Kickul and Neuman 2000). Conscientiousness has been associated with heightened levels of adherence to rules regarding attendance, punctuality, and respect for group processes. Studies have shown that conscientious group members were more task orientated and less likely to engage in social loafing (Konovsky and Organ 1996). Agreeableness has been linked to sportsmanship and inclination to absorb minor inconveniences and impositions accruing from the job (Konovsky and Organ 1996). Studies show that members high in agreeableness contribute to the social functioning of their team (Antonioni 1998). Similarly, emotional stability appears to be a requisite for coordinating the behaviors of teammates and the ability to withstand temperamental and impulsive behaviors of others. Conversely, neuroticism has been coupled with fear of negative evaluations, social avoidance, and preference for individual work (Cantwell and Andrews 2002). Finally, openness has been negatively related to hypercompetitive attitudes. A study by Ross, Rausch, Canada (2003) showed that openness was positively related to cooperative behaviors - although none of the identified results were statistically significant.

Lonnsbury, Smith, and Levy (2009) found that business students scored higher than non-business students on conscientiousness, emotional stability, extraversion, assertiveness, and tough-mindedness, but scored lower on 
agreeableness and openness. Other findings indicate that personality traits differ systematically among students depending upon business functional areas. A study by Noel, Michael, and Levas (2003) found that accounting, marketing, and management information majors differed on extraversion, emotional stability, and openness.

Additional studies suggest that personality is linked to attitudes toward working in groups. This is notable because group learning plays a central role in business education and because learning outcomes are strongly influenced by the quality of communications, and participation among team members (Napier 2007).

Cantewell and Andrews found that higher levels of sociability and lower levels of social anxiety were associated with preference for group work and stronger mastery and performance goals. By contrast, enhanced levels of social anxiety combined with lower levels of sociability were associated with discomfort in group settings (Cantwell and Andrews 2002). This finding was corroborated in a study by Brown, Poole, and Rogers (2004) who found that neuroticism was associated with lower levels of ability to collaborate in groups. These relationships were explored more fully in this study by examining the concurrence of Neo-FFI personality indicators with indicators of attitudes toward academic group work.

\section{METHOD}

Subjects for the study were 225 business students (54 percent male) from a southeastern university. The students were working adults, ranging in age from 20 to 52 with a mean age of 26.7 years. Sixty percent of students reported working full-time and 28 percent were working part-time. Only 11 percent of students were not employed at the time of the survey. Years of full time work experience ranged from 0 to 32 with a mean of 5.9 years. The average for part-time work experience was 4.8 years. Data were collected over a four-semester span in nine sections of three different marketing courses. Students comprised 45 teams ranging in size from three to seven members with four being the modal team size. Students participated in the study for course credit.

Within each course, data were collected in three phases. During the first phase the students were organized into teams. Team memberships were voluntary; however, in some instances the instructor reassigned students to groups that contained fewer members. In the second phase, students provided baseline personality information along with indications of their attitudes toward academic group work. In the final phase, students provided demographic and work related data for classification purposes.

Personality information was collected using the Neo Five-Factor Inventory (Neo-FFI). This inventory provides a comprehensive sketch of each student's emotional, interpersonal, experiential, attitudinal, and motivational styles (Costa and McCrae 1992). It consists of 60 Likert-type items anchored by $1=$ strongly disagree to $5=$ strongly agree and measures respondents' personality on the five dimensions of agreeableness, conscientiousness, extraversion, neuroticism and openness.

Phase two data collection took place approximately six weeks later, after teams had sufficient time to work together on a variety of tasks. In phase two, students provided information about their interactions with other people using the Fundamental Interpersonal Relations Orientation - Behavior instrument (FIRO-B) (Schutz 1958). This 54-item instrument measures three dimensions of interaction with others: inclusion, control, and affection.

During phase two, students also completed an 18-item inventory measuring feelings and attitudes toward group work (Cantwell and Andrews 2002; Gardner and Korth 1988). Dimensions measured by these items include preference for group work, attitudes toward academic group work and discomfort in groups. The last phase of data collection was conducted at the end of the semester. At that time, students indicated their perceptions of team effort, team effectiveness, and their satisfaction with performance of team tasks.

Three ANOVAs were conducted to determine the appropriateness of pooling data across groups, classes and semesters. Semesters, classes and group membership were the independent variables and the scores on each dimension of Neo-FFI were the dependent variables. The ANOVA results indicated no significant differences in personality across groups, classes, or semesters. Therefore pooled data were used in the subsequent analysis. 


\section{ANALYSIS}

The five dimensions of Neo-FFI scales were designated as independent variables and preference for group work, attitudes toward academic group work, and discomfort in group learning were the dependent measures. Table 1 presents scale means and Cronbach's alphas for independent and dependent variables. Results indicate adequate levels of reliability for all scales. Following the approach suggested by Antonioni (1998), three hierarchical regression models were computed for each work group scale. Age and gender were introduced into the models first. The five personality factors were then introduced into the models in a step-wise fashion. Table 2 summarizes results of the regression analysis.

Table 1: Scale Properties for Personality and Attitudes toward Academic Group Work

\begin{tabular}{lcccc} 
& $\begin{array}{c}\text { Number of } \\
\text { Items }\end{array}$ & $\begin{array}{c}\text { Scale } \\
\text { Mean }\end{array}$ & $\begin{array}{c}\text { Item } \\
\text { Mean }\end{array}$ & $\begin{array}{c}\text { Cronbach's } \\
\text { Alpha }\end{array}$ \\
\cline { 2 - 5 } $\begin{array}{llll}\text { Personality Measures (Independent Variables) } \\
\text { Agreeableness }\end{array}$ & & & & \\
Conscientiousness & 12 & 43.85 & 3.65 & 0.721 \\
Extroversion & 12 & 46.45 & 3.87 & 0.832 \\
Neuroticism & 12 & 44.51 & 3.71 & 0.802 \\
Openness & 12 & 29.42 & 2.45 & 0.862 \\
& & 40.11 & 3.34 & 0.677 \\
Group Work Attitudes (Dependent Variables) & & & & \\
Attitudes Toward Academic Group Work & 7 & 25.26 & 3.31 & 0.899 \\
Discomfort in Group Work & 4 & 7.94 & 2.12 & 0.632 \\
Preference in Group Work & 7 & 26.73 & 3.82 & 0.646
\end{tabular}

Table 2: Regression Analysis of Personality Variables on Attitudes toward Academic Group Work

\begin{tabular}{lccccccc} 
& \multicolumn{3}{c}{ Neo-FFI Personality Variables } & \multicolumn{3}{c}{ Model } \\
\cline { 2 - 9 } Regression & $\begin{array}{c}\text { AGR } \\
\text { (b3) }\end{array}$ & $\begin{array}{c}\text { CON } \\
\text { Model }\end{array}$ & $\begin{array}{c}\text { EXT } \\
\text { (b5) }\end{array}$ & $\begin{array}{c}\text { NRT } \\
\text { (b6) }\end{array}$ & $\begin{array}{c}\text { OPN } \\
\text { (b7) }\end{array}$ & P-value & R \\
\hline Attitudes toward Academic Group Work & & & $\mathbf{0 . 4 0 9}$ & & & 0.001 & 0.413 \\
Discomfort in Group Learning & & & $-\mathbf{0 . 2 3 9}$ & $\mathbf{0 . 4 5 1}$ & & 0.001 & 0.578 \\
Preference in Group Learning & $\mathbf{0 . 1 3 5}$ & $\mathbf{0 . 1 7 4}$ & $\mathbf{0 . 2 5 4}$ & & & 0.001 & 0.477 \\
\hline
\end{tabular}

AGR $=$ Agreeableness, CON $=$ Conscientiousness, EXT $=$ Extroversion, NRT $=$ Neuroticism, OPN $=$ Openness

All Bolded Coefficients are Significant at $p<0.05$

In the present study, age and gender had no impact on any of the group work attitude scales and were therefore not included in Table 2. It appears that males and females have similar attitudes and feelings with regard to academic group work. Since the majority of respondents in our sample were between 23 and 34 years of age, we believe that the truncated range of age might have masked any potential relationship that it might have with group work attitudes.

Extroversion was the single best predictor of respondents' attitudes toward academic group work. Individuals with high extroversion scores had positive attitudes toward academic group work $\left(b_{5}=0.409, p<0.05\right)$. Extroversion and neuroticism were significant predictors of discomfort with group learning. High levels of extroversion resulted in lower levels of group learning discomfort $\left(b_{5}=-0.239, p<0.05\right)$, while high scores on neuroticism score related to higher levels of discomfort in group learning $\left(b_{6}=0.451, p<0.05\right)$. Agreeableness $\left(b_{3}\right.$ 
$=0.135, \mathrm{p}<0.05)$, conscientiousness $\left(\mathrm{b}_{4}=0.174, \mathrm{p}<0.05\right)$ and extroversion were all positively related to respondents' preference for group learning with extroversion having the most significant effect $\left(b_{5}=0.254, p<\right.$ 0.05). As such, extroversion was the most important predictor of work group attitudes for all three dependent measures. Interestingly, respondents' level of openness had no impact on any of the work group attitude variables.

\section{DISCUSSION}

The findings confirmed the premise that personality affects work group attitudes and that the direction and magnitude of influence varies among personality dimensions. Additional analysis was undertaken to explore these influences more fully. This involved correlating the four statistically significant Neo-FFI scales with individual items from each of the dependent measure scales (Table 3).

Table 3: Correlation Coefficient among the Significant Neo-FFI Variables and Group Work Attitudes Items

\begin{tabular}{|c|c|c|c|c|}
\hline \multicolumn{2}{|l|}{ 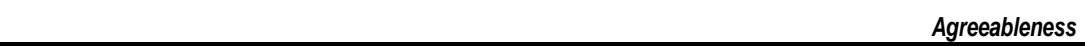 } & \multirow[t]{2}{*}{ Conscientiousness } & \multirow[t]{2}{*}{ Extroversion } & \multirow[t]{2}{*}{ Neuroticism } \\
\hline Attitudes toward Academic Group Work & & & & \\
\hline Group work helps me learn better & & & 0.302 & \\
\hline I enjoy participating in group work & & & 0.408 & \\
\hline Group work is a productive use of class time & & & 0.336 & \\
\hline Group work engages my interest & & & 0.321 & \\
\hline I find it easier to learn in group & & & 0.301 & \\
\hline I learn best when I am working alone--REVERSED & & & 0.351 & \\
\hline When I learn someting in a group setting, I tend to remember more than if I learn if from a lect & ture & & 0.174 & \\
\hline \multicolumn{5}{|l|}{ Discomfort in Group Learning } \\
\hline I sometimes feel nervous when I have to give my ideas or communicate within group & & & -0.385 & 0.446 \\
\hline I often find it difficult to understand what the group task is & & & -0.083 & 0.331 \\
\hline I am often afraid to ask for help within my group & & & -0.261 & 0.418 \\
\hline I rarely feel relaxed within a group & & & -0.279 & 0.251 \\
\hline \multicolumn{5}{|l|}{ Preference in Group Learning } \\
\hline I understand information better after explaining it to others in a group & 0.115 & 0.063 & 0.228 & \\
\hline I often have a strong feeling of satisfaction when I become totally involved in group achievem & 0.262 & 0.141 & 0.278 & \\
\hline I usually make a strong personal contribution to group work & 0.187 & 0.307 & 0.178 & \\
\hline I like group work more when we can make up our own group & 0.032 & 0.134 & 0.181 & \\
\hline I can usually understand other group members ideas & 0.079 & 0.228 & 0.221 & \\
\hline It is best when each person helps each other within a group & 0.191 & 0.244 & 0.202 & \\
\hline
\end{tabular}

All Bolded Coefficients are Significant at $p<0.05$

The pattern of significant correlations indicated that individuals high on extroversion enjoyed participating in groups and believed that group work was a productive use of class time. They were engaged and tended to learn more in group work setting than from lectures alone. Their ability to explain information to other group members helped them understand the concepts better. They had a strong sense of satisfaction when involved in group achievement. They were also relaxed in group settings, could express and communicate their ideas and were not afraid to ask for help. In summary, individuals who enjoy talking to other people; are energetic, high spirited and cheerful are likely to do well in groups and contribute to group work.

Neuroticism is the other personality factor that impacted students' comfort in group learning. Neurotic individuals reported feeling nervous in communicating their ideas within group, had difficulty understanding what the group task was; were not relaxed and were afraid to ask for help within their group. These are individuals who are worriers and often feel inferior to others. Furthermore, they have a limited capacity in dealing with stressful situations and get angry at the ways other treat them. As such, their participation and contribution to group work will be limited. 
Agreeableness and conscientiousness also impacted group work attitudes, in particular, preference in group learning. Agreeableness was positively correlated with level of personal contribution to group work and students' satisfaction when they became involved in group achievement. Conscientious individuals liked group work more when they selected their own groups. They understood other group members' ideas and were willing to offer help to group members. These individuals tend to be courteous and willing to cooperate rather than compete with others. They also perform all tasks assigned to them conscientiously and work hard to accomplish their goals. In group work setting one can always count on them to follow through with their commitments.

\section{CONCLUSIONS}

The present study contributes to the emerging body of literature that examines the role of personality on group work attitudes. Generally, findings are consistent with previous studies and reaffirm the premise that personality affects the willingness of students to enter into and actively participate in learning collaborations. The direction and relative magnitude of correlations for extroversion and neuroticism are consistent with previous studies. Previous studies have shown significant correlations between willingness to assume leadership roles within learning groups, but have been inconsistent in linking openness with the dependent measures used here.

Some previous studies have found gender differences in attitudes toward learning experiences and toward behaviors. A study by Kaenzig et al (2007) found that women differed from men in their post-hoc evaluation of their business education experiences and had preferences for less formality in interacting with other students. Underwood (2003) showed gender differences in attitudes toward anti-social behaviors within learning groups. Lack of significant gender differences in this study were not surprising, given the focus on general group work attitudes, preferences and comfort.

This study broadens the range of populations across which results can be generalized. Previous studies have used non business subjects; i.e., psychology students, secondary school students, or teachers in training (Kickul and Neuman 2000, Cantwell and Andrews 2002, Underwood 2003). In studies that have used business student subjects, selection has been specific to particular functions; e.g., graduate students in HR Management or IT students enrolled in online classes (Gardner and Korth 1998, Napier and Johnson 2007). This study used both undergraduates and graduates from a cross-section of functional areas and majors indicating that results can be generalized across a broader population of business students than previously thought.

\section{AUTHOR INFORMATION}

William Forrester received his Ph.D. in Marketing in 1986 from the University of Tennessee. He currently works as Professor of Marketing in the Coles College of Business at Kennesaw State University. He has published in numerous outlets including the Journal of the Academy of Marketing Science, the Journal of Economic Psychology, and the Journal of Applied Business Research.

Armen Tashchian is Professor of Marketing in the Coles College of Business at Kennesaw State University. He received his Ph.D. in Marketing from the University of Texas in 1980. He has published in numerous academic journals including the Journal of Marketing, the Journal of Marketing Research, and the Journal of the Academy of Marketing Science.

\section{REFERENCES}

1. Bobbitt, L. Michelle, Scott A. Inks, Katie J. Kemp and Donna T. Mayo (2000), "Integrating Marketing Courses to Enhance Team-Based Experiential Learning," Journal of Marketing Education, 22,1, 15-24.

2. Brown, Houghton G., Marshall S. Poole, and Thomas L. Rogers (2004),'Interpersonal Traits, Complementarity, and Trust in Virtual Collaboration,” Journal of Management Information Systems, 20, 4, $115-137$.

3. Cantwell, Robert H. and Beverly Andrews (2002), "Cognitive and Psychological Factors Underlying Secondary School Students' Feelings towards Group Work,” Educational Psychology, 22, 1, 75-90. 
4. Costa, Paul T. and Robert R. McCrae (1992), Neo PI-R and Neo-FFI Professional Manual. Odessa, FL: Psychological Assessment Resources, Inc.

5. Gardner, Brenda S. and Sharon J. Korth (1998)., “A Framework for Learning to Work in Teams,: Journal of Education for Business, 74, 1, 28-33.

6. Huff, Lenard C., Joanne Cooper, and Wayne Jones (2002), "The Development and Consequences of Trust in Student Project Groups," Journal of Marketing Education, vol. 24, no. 1., pp. 24-34.

7. Kaenzig, Rebecca, Eva Hyatt, and Stella Anderson (2007), "Gender Differences in College of Business Educational Experiences,” Journal of Education for Business, 95-100.

8. Kickul, Jill and George Neuman (2000), "Emergent Leadership Behaviors: The Function of Personality and Cognitive Ability in Determining Teamwork Performance and KSAS," Journal of Business and Psychology, 15, 1, 27-30.

9. Konovsky, Mary A. and Dennis W. Organ (1996), "Dispositional and Contextual Determinants of Organizational Citizenship Behavior”, Journal of Organizational Behavior, 17, 253-266.

10. Lounsbury, John W., Ryan M. Smith, Jacob J. Levy, Frederick T. Leong, and Lucy W. Gibson (2009), "Personality Characteristics of Business Majors as Defined by the Big Five and Narrow Personality Traits," Journal of Education for Business, 84, 4, 200-205.

11. McCorkle, Denny E., James Reardon, Joe F. Alexander, Nathan D. Kling, Robert C. Harris, and R. Vishwanathan Iyer (1999), "Undergraduate Marketing Students, Group Projects and Teamwork: The Good, the Bad, and the Ugly?" Journal of Marketing Education, vol. 21, no. 2., pp. 106-117.

12. Napier, Nannette P. and Roy D. Johnson (2007), Technical Projects: Understanding Teamwork Satisfaction in an Introductory IS Course," Journal of Information Systems Education, 18, 1, 39-48.

13. Noel, Mark N., Chad Michael, and Michael G. Levas (2003), "The Relationship of Personality Traits and Self-Monitoring Behavior to Choice of Business Major," Journal of Education for Business, 78, 3, 153157.

14. Pineda, Rodney C. and Linda D. Lerner (2006), "Goal Attainment, Satisfaction, and Learning from Teamwork," Team Performance Management, 12, 5/6, 182-191.

15. Ross, Scott R, K. Karega Rausch, and Kelli E. Canada (2003), "Competition and Cooperation in the FiveFactor Model: Differences in Achievement Orientation," The Journal of Psychology, 137, 4, 323-337.

16. Schellens, T, H. Van Keer, M. Valcke and B. De Wever (2007), "Learning in Asynchronous Discussion Groups: A Multilevel Approach to Study the Influence of Student, Group, and Task Characteristics," Behavior and Information Technology, 26, 1, 55-71.

17. Shaw, Jason D., Michelle K. Duffy and Eric M. Stark (2000), "Interdependence and Preference for Group Work: Main and Congruence Effects on the Satisfaction and Performance of Group Members," Journal of Management, vol. 26, no. 2, pp. 259-279.

18. Eric M. Stark, Jason D. Shaw and Michelle K. Duffy and (2007), 'Preference for Group Work, Winning Orientation, and Social Loafing Behavior in Groups," Group and Organizational Management, 32, 6, 699. 723.

19. Thompson, DeWayne, Ismet Anitsal, and Hilton Barrett (2008)," Attitudes toward Teamwork in Higher Education: A Comparative Study of Religiously Affiliated Universities and Secular-Based Universities," Proceedings of the Academy of Educational Leadership, vol. 13, no. 2.

20. Underwood, Jean D. M. ( 2003), "Student Attitudes toward Socially Acceptable and Unacceptable Group Work Practices," British Journal of Psychology, 94, 319-337. 
NOTES 